\title{
Damage Identification of Slab-girder Structures: Experimental Studies
}

\author{
Ying Wang ${ }^{1}$ and Hong Hao ${ }^{2}$ \\ ${ }^{1}$ School of Engineering, Deakin University, Waurn Ponds, VIC, Australia. \\ Phone: +61-3-52272106 \\ Fax: +61-3-52272028 \\ Email: ying.wang@deakin.edu.au \\ ${ }^{2}$ School of Civil and Resource Engineering, the University of Western Australia, \\ Crawley, WA, Australia.
}

\begin{abstract}
Slab-girder structures composed of steel girder and reinforced concrete slab are widely used in buildings and bridges in the world. Their advantages are largely based on the composite action through the shear connection between slab and girder. In order to assess the integrity of this kind of structures, numerous vibration-based damage identification methods have been proposed. In this study, a scaled composite slab-girder model was constructed in the laboratory. Some removable shear connectors were specially designed and fabricated to connect the girder and slab that were cast separately. Then, a two stage experiment including both static and vibration tests was performed. In the first stage, vibration tests were conducted under different damage scenarios, where a certain number of shear connectors at certain locations were removed step by step. In the second stage, two sets of hydraulic loading equipment were used to apply four point static loads in the test. The loads are increased gradually until concrete slab cracked. The loading histories as well as deflections at different points of the beam are recorded. Vibration test was carried out before and after concrete cracking. Experimental results show that the changes of mode shapes and relative displacement between slab and girder may be two promising parameters for damage identification of slab-girder structures.
\end{abstract}

Keywords: Slab-girder structure; Shear connector; Static test; Vibration test; Mode shape. 


\section{Introduction}

In civil engineering practices, composite steel and concrete systems are widely used in bridges and long-span building floors (Johnson 2004). These systems take advantage of both concrete and steel materials and minimize their disadvantages. In a typical slab-girder structure, steel girder is used to resist tension forces caused by bending moments due to its strength advantage. On the other hand, concrete slab provides not only the compression strength but also continuous restraints for the steel girder against lateral deflection, so that the steel girder can be designed as a compact beam and there will be no flexural-torsional buckling failure for the steel girder. The strength of a fully-interacted system can be several times higher than that of a detached system. Also, deflection can be largely reduced because of the increased effective second moment of inertia.

To achieve composite action in this kind of system, the shear connection between concrete slab and steel girder plays an important role by transferring shear forces between slab and girder. However, due to corrosion, fatigue, unexpected overloading, and other factors, the condition of the connectors may degrade. Damage or failure of shear connectors may largely reduce the load-carrying capacity and stiffness of the composite systems, or even cause their early failure. Therefore, the condition assessment of shear connectors is apparently significant for evaluating the safety of the whole composite system.

However, the shear connectors are physically inaccessible for visual inspection and the traditional non-destructive techniques, because they are usually cast in the concrete slab. Vibration-based condition assessment methods have been found promising for detecting shear connector conditions (Dilena and Morassi 2009). In the last few decades, numerous vibration-based methods have been developed to identify and assess structures with various damages. The theoretical background of vibration-based method is that when damage occurs in a structure, its modal parameters, including natural frequencies, mode shapes and damping ratios, will change. For more detailed information on this kind of methods, Doebiling et al. (1998) and Sohn et al. (2003) provided informative reviews. 
Recently, several research groups have placed their research focuses on damage identification of composite systems. Morassi and Rocchetto (2003) and Dilena and Morassi (2003) presented experimental studies and numerical simulation on damage-induced changes in modal parameters of composite beams. The results show that flexural modes are more sensitive than other modes for damage detection. In Dilena and Morassi (2009), an Euler-Bernoulli model of composite beam was built, which can accurately describe the vibration response measured on composite beams with either severe or intermediate levels of damage. A diagnostic method based on shift frequency data was then applied for damage identification. Liu and De Roeck (2009) proposed a damage indicator based on the local modal curvature and the wavelet transform modulus maxima for stud damage identification. Shih et al. proposed a multi-criteria-based damage detection method for slab-girder structures. In addition to change in natural frequencies, modal flexibility and modal strain energy are incorporated and reliable damage detection results can be yielded. Since 2007, the research group in the University of Western Australia has conducted a series of studies on various methods for the shear connector damage detection. Xia et al. (2007) developed an innovative damage index based on the difference of frequency response functions on the slab and the corresponding points on the girder to evaluate the condition of shear connectors. The results show that this approach, which does not require any baseline data from the structure, was able to detect all the damage successfully and consistently. Xia et al. (2008) further demonstrated the eligibility of the method for application to the bridges, which is more reliable and accurate in assessing the shear connector condition, than the traditional model updating techniques. Based on the experimental results, Ren et al. (2008) proposed a signal-based damage identification method by using wavelet packet-based energy index. It was suggested to be used to determine damage location only or to be a complementary technique to other quantitative damage identification algorithm. In order to overcome the modal perturbation problem, Bao et al. (2009) improved the Hilbert-Huang Transform (HHT) method by using the auto-correlation function as input, adding a band-pass filter and combining an effective intrinsic mode function selection principle. This method was successfully used for damage identification of a concrete-steel composite beam. Zhu et al. (2012) proposed a method based on Kullback-Leibler distance to assess the integrity of the shear connectors. Vibration tests were conducted on a bridge model in the 
laboratory and the results showed that the proposed method can detect all the assumed damage scenarios.

In this study, a scaled composite slab-girder model was constructed in the laboratory. Six sets of removable shear connectors were specially designed and fabricated to link the beams and slab that were cast separately. Then, a two-stage experiment was performed. In the first stage, a certain number of shear connectors at certain locations would be removed to simulate different damage scenarios. Vibration tests were carried out under different damage scenarios. In the second stage, two static loads were applied on the $1 / 3$ points of the structure. The loads were increased step by step until concrete slab cracked. The deflection and loading histories are recorded. Vibration tests were also conducted. Both static and vibration results are used to identify damage in the structure.

\section{EXPERIMENTAL SETUP}

\section{Specimen description}

A composite slab-girder structure was designed in accordance with AS2327.1 (2003), as shown in Fig. 1 (a). It comprised of a 200UB22.3 steel member and a Grade 40 concrete slab with a depth of $100 \mathrm{~mm}$ and a width of $1000 \mathrm{~mm}$. The longitudinal and transverse slab reinforcement was provided by a $100 \mathrm{~mm} \times 100$ $\mathrm{mm} \times 5 \mathrm{~mm}$ thick mesh sheeting. The slab-girder system was simply supported, with a span of $6 \mathrm{~m}$. The span was selected to fulfil both technical and practical requirements, specifically large enough to perform tests under several damage scenarios while not exceeding the allowable laboratory space. The shear connection between the steel and concrete members was designed and constructed using 20 mm 8.8/S bolts with $300 \mathrm{~mm}$ spacing. Two types of connectors were used: the headed stud and the removable bolt (Fig. 1 (b) and (c)). The headed studs were installed by welding $20 \mathrm{~mm}$ high strength structural bolts in the middle section of the composite beam. The removable bolt was designed to simulate both undamaged and damage states, located both 1/4 parts near the ends as shown in Fig. 1(d). The holes were punched in the steel beam, and $80 \mathrm{~mm}$ long nuts were welded to cover them. After concrete was poured, the nuts were permanently fixed and provided 
anchorage for the shear connector. The connection was then completed by threading the bolts through the encased nuts.

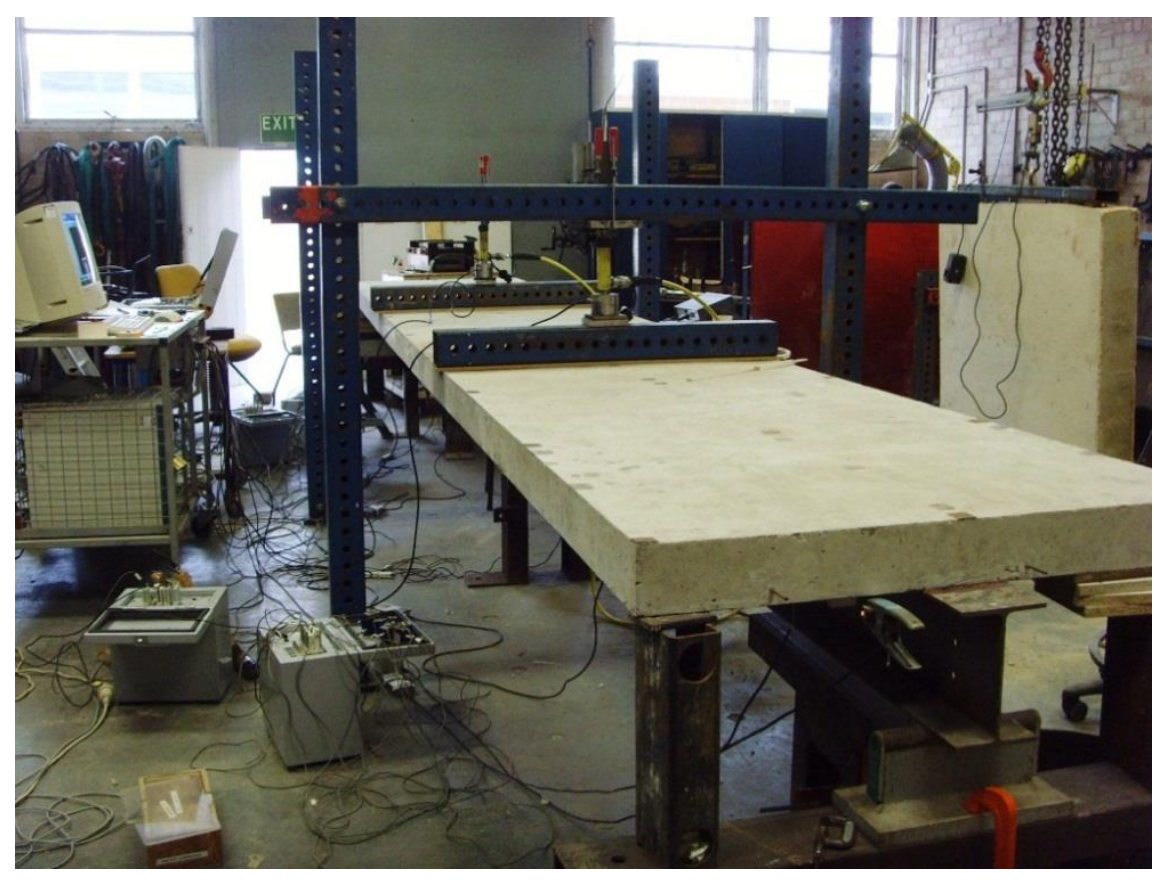

a) Slab-girder system

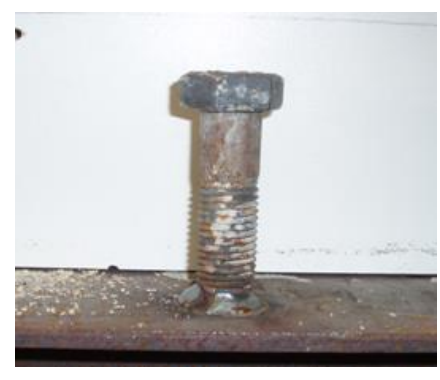

b) Headed stud

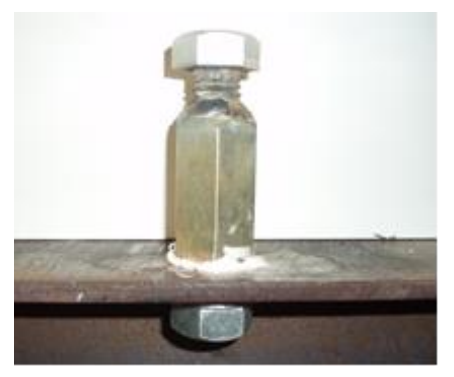

c) Removable shear connector

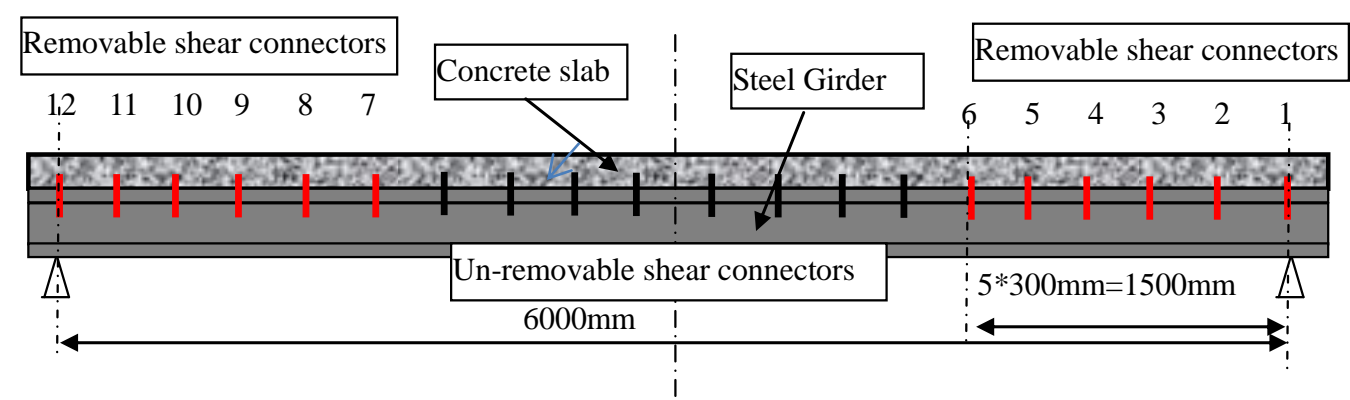

d) Removable shear connector locations

Figure 1 Slab-girder system 


\section{Test procedure}

In order to examine the suitability and efficiency of various vibration-based damage identification methods for structural condition assessment, a two-stage test was conducted. In the first stage, damage was introduced into the system by removing a certain number of shear connectors from different locations. In the second stage, all the removable bolts were removed. Then, two static loads were applied at the $1 / 3$ points of the structure. These loads were increased step by step until inducing crack damage on the concrete slab. Totally, six damage scenarios were explored in this study ranging from an undamaged case (DS0) to final damaged case (DS5) when structures were loaded until concrete cracked. The damage cases are summarised in Table 1, where S1-S12 indicate No. 1 to No.12 shear connectors shown in Fig. 1(d).

Table 1 Damage scenarios

\begin{tabular}{|l|l|l|}
\hline Stage & Damage scenarios & Description \\
\hline \multirow{3}{*}{ Stage 1 } & DS0 & Intact \\
\cline { 2 - 3 } & DS1 & Removal of S1 \& S2 \& (S12 \& S11) \\
\cline { 2 - 3 } & DS3 & Removal of S1 \& S2 \& S5 \& S6 \& (S12 \& S11) \\
\hline \multirow{2}{*}{ Stage 2 } & DS4 & Removal of S1 \& S2 \& S5 \& S6 \& (S12 \& S11 \& S8 \& S7) \\
\cline { 2 - 3 } & DS5 & Removal of all the removable bolts \\
\hline
\end{tabular}

The vibration test system, as shown in Fig. 2, mainly consists of three parts: 1) an impact hammer to provide impulse load; 2) the accelerometers to measure acceleration on the structure; 3 ) the data transmission devices to collect data from sensors and to transfer them to the computer. For each damage scenario, the vibration tests were conducted by exciting the beam with an instrumented impact hammer (Type 5802A from Dytran Instruments Inc.) and recording structural accelerations by nine accelerometers. The responses of the composite structure were obtained at 36 locations which were divided into four sets of data: Set 1 (locations 1-9), Set 2 (locations 10-18) and Set 3 (locations 19-27) on the slab and Set 4 (locations 28-36) on the steel beam, the sensors were distributed as shown in Fig. 3. Six impact tests were performed in each set for each damage case to get an averaged result. 


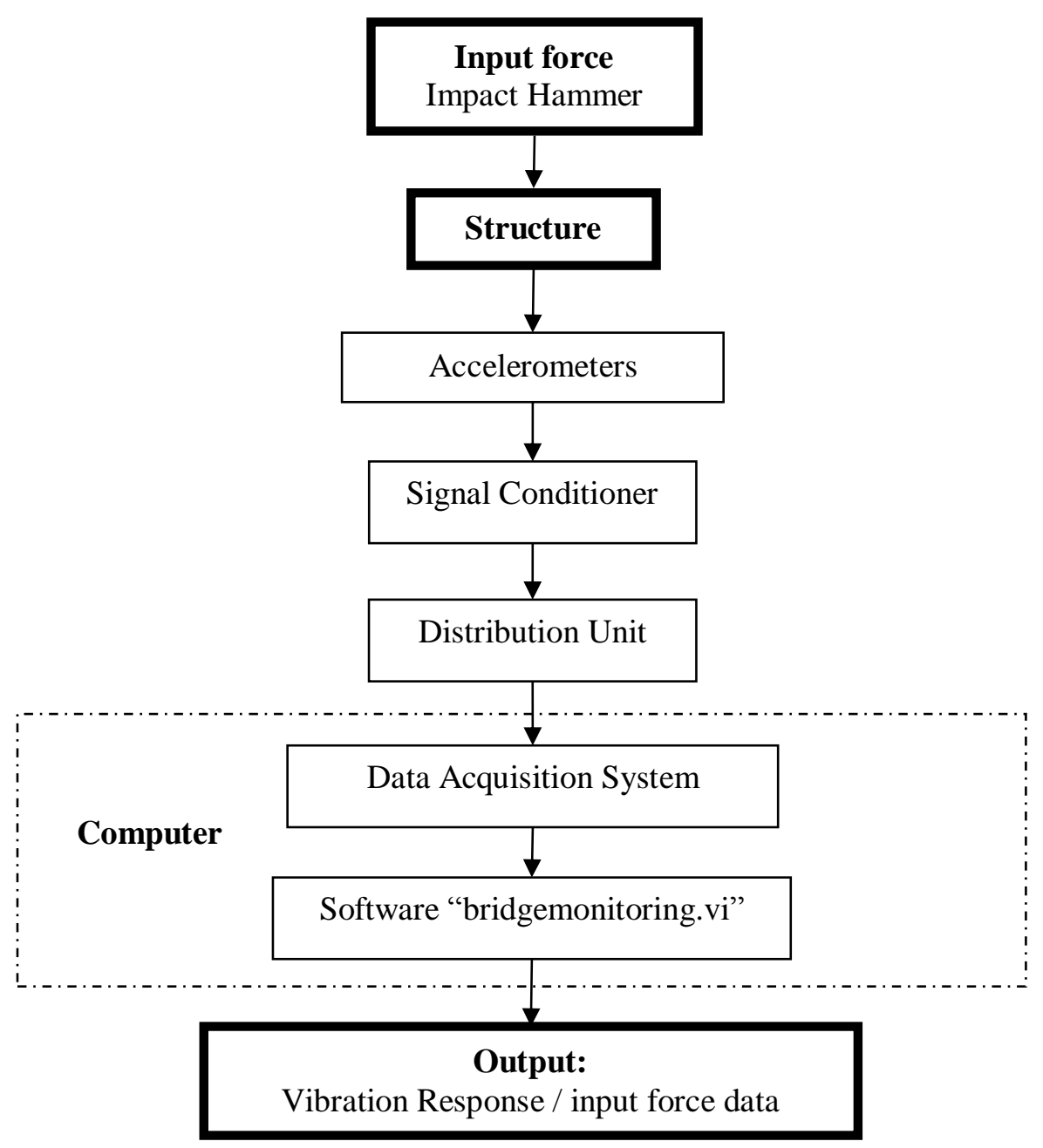

a) Vibration test system

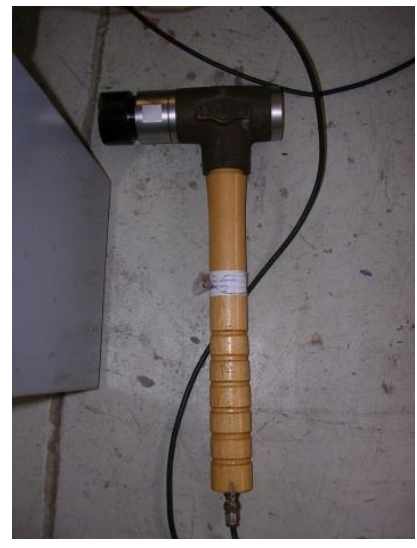

b) Impact hammer

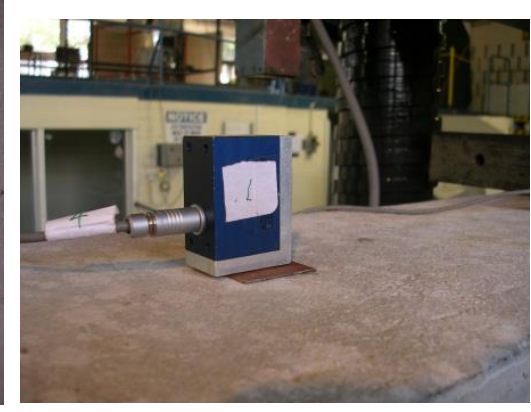

c) Accelerometer

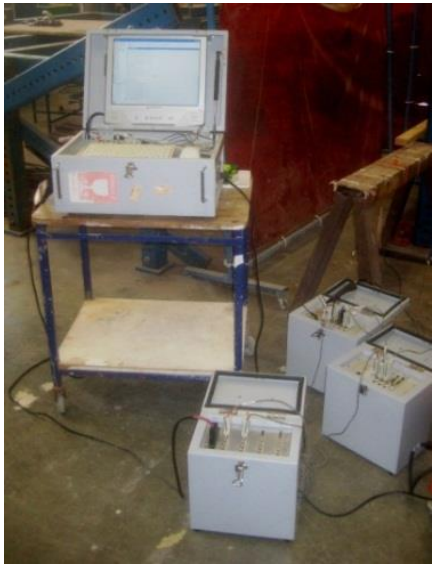

d) Unit boxes and computer

Figure 2 Vibration test system

For static test, two sets of hydraulic loading equipment were used to apply static loads on the slab-girder system, as shown in Fig. 4. The locations are illustrated in 
Fig 4(a). Loading history was recorded by using the load cell, symbolised by a red circle in Fig. 4 (c). The deflections at different locations of the structure were also recorded by using laser and spring displacement sensors for monitoring purposes, as shown in Fig. 5. In order to take unexpected vertical displacements at the support locations into consideration, three spring displacement sensors were placed vertically under the beam. Two of them were next to the supports and the other one was at the middle of the beam, as shown in Fig. 5(b). Further, six laser displacement sensors were placed horizontally to monitor the relative displacement between the concrete slab and steel girder. As can be seen in Fig. 5(c), a white wood plate was used together with the lasers. The plates were attached on the concrete slab while the laser sensors were fastened at the steel girder by using the clamps. Totally, six laser sensors and three spring sensors were used in this study. Their locations were shown in Fig. 5(a).
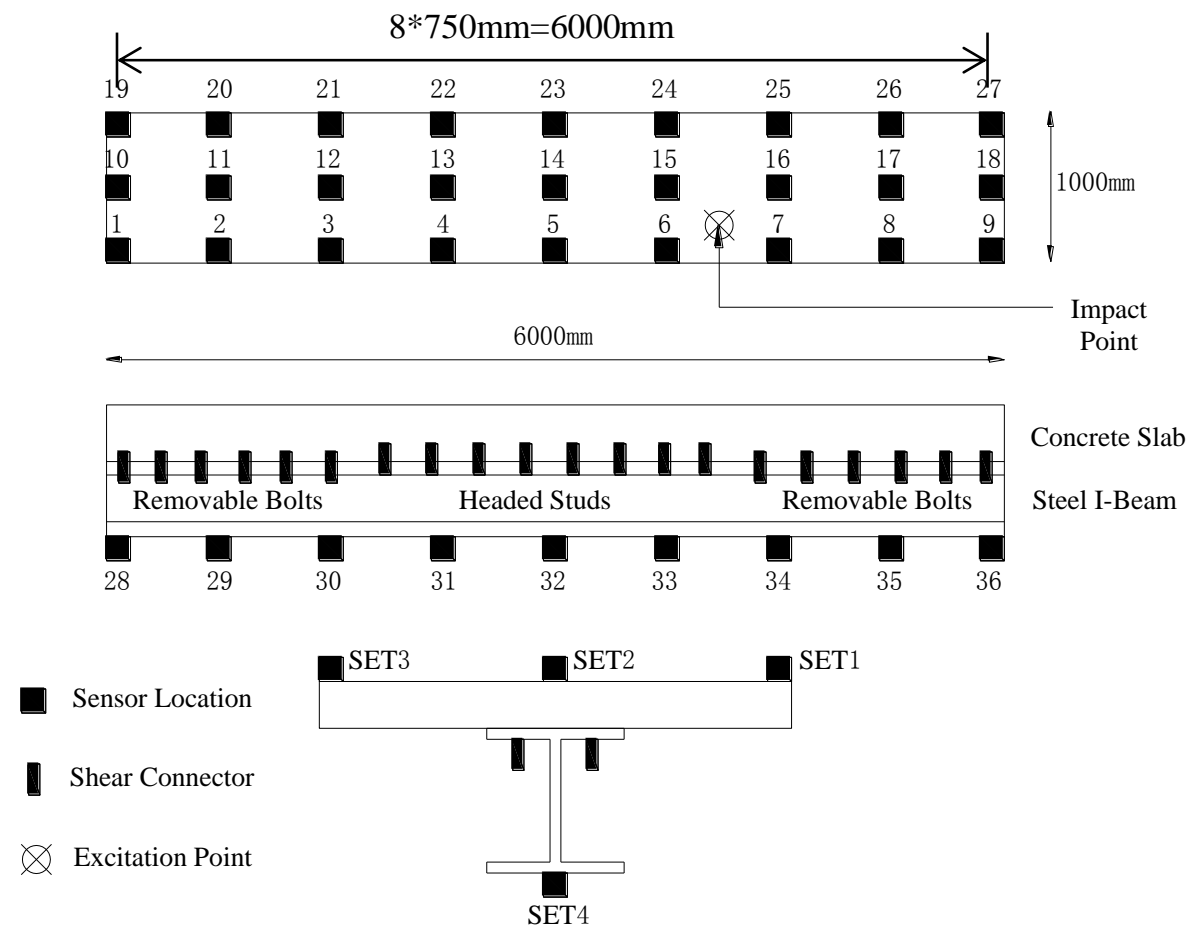

Figure 3 Sensor locations 


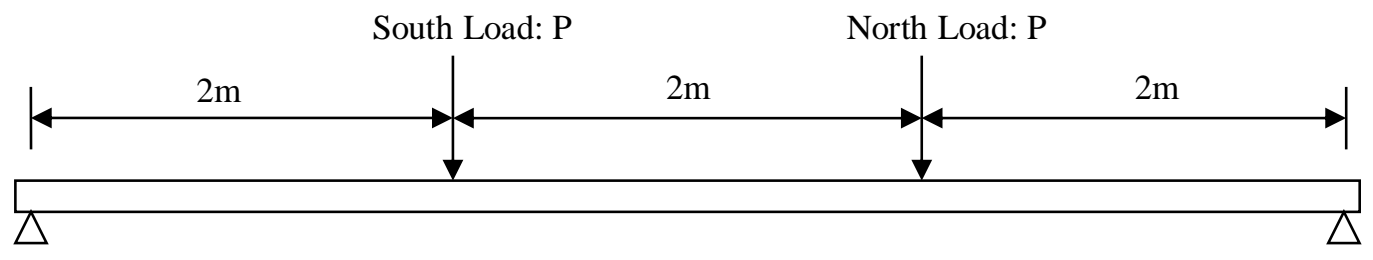

a) Locations of static loads

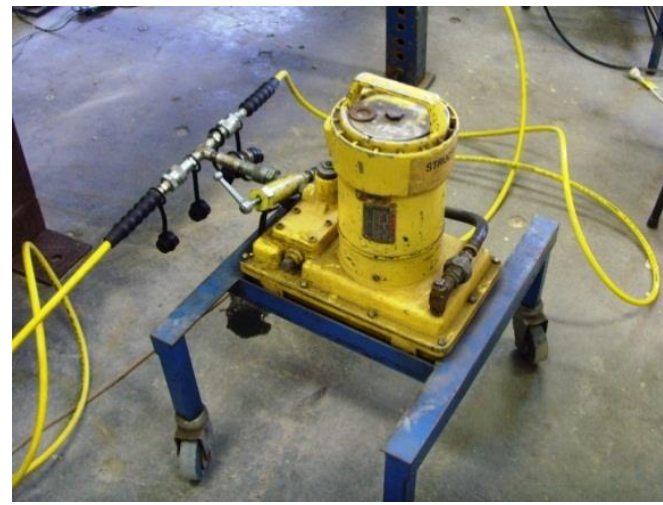

b) Hydraulic equipment

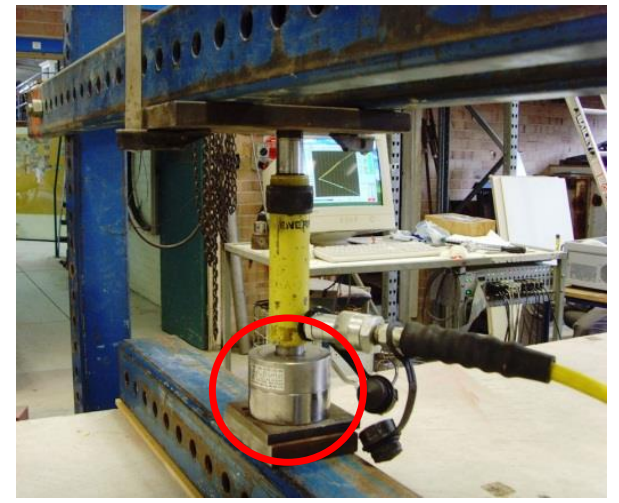

c) Load cell and hydraulic equipment

Figure 4 Static loading system

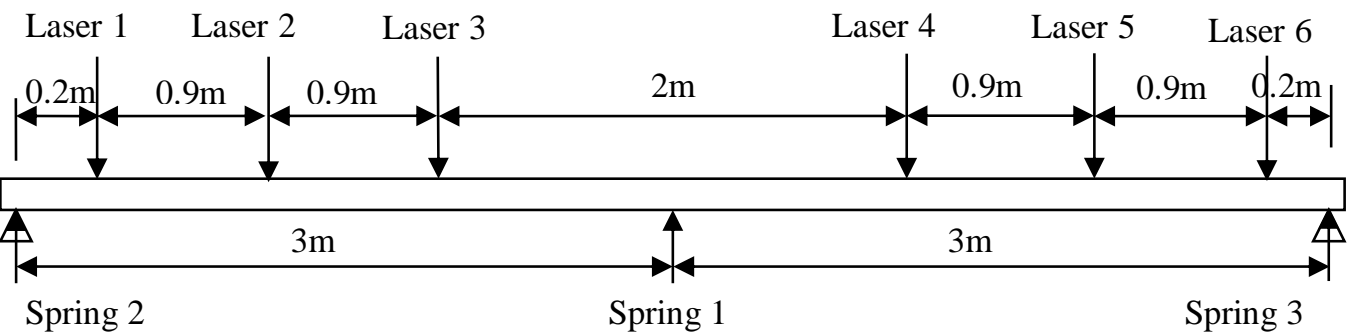

a) Locations of displacement sensors

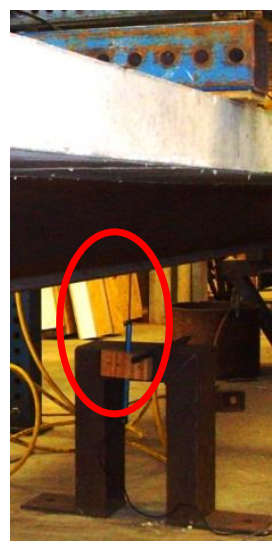

b) Spring displacement sensor

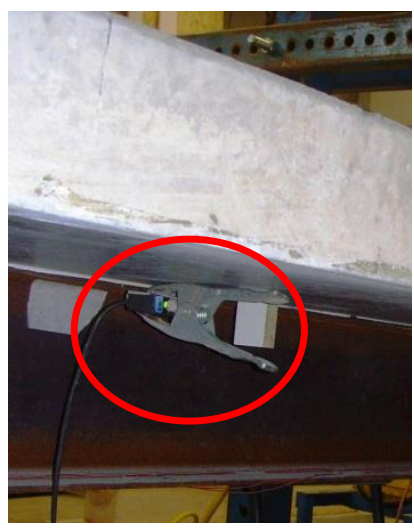

c) Laser displacement sensor

Figure 5 Deflection monitoring system 


\section{EXPERIMENTAL RESULTS}

\section{Stage 1}

In the first stage, only the vibration tests were conducted. In these tests, $2000 \mathrm{~Hz}$ was taken as the sampling rate. Based on Shannon's sampling theorem, the vibration modes with natural frequency smaller than $1000 \mathrm{~Hz}$ can be identified by using DIAMOND (LANL), a graphic interface toolbox for modal analysis. The results of identified natural frequencies are summarised in Table 2. It should be noted that the second channel of the testing system was faulty, and thus the second sensor of each set had no result.

As can be seen, for the intact structure, totally 28 modes can be identified, including 8 bending modes, 8 torsional modes and 12 local modes. It should be noted that in the local modes, only part of the structure vibrates, i.e., left south part of the concrete slab. For shear connector removal damage cases, specifically DS1, DS2 and DS3, five/six local modes together with one torsional mode cannot be identified, specifically No. 11, 12, 21, 24 and 27. For those identified, the changes of natural frequencies are very small ( $-2.36 \%$ at most). In contrast, the mode shape changes are obvious. Some of the mode shapes for damaged cases show apparent discrepancy between steel girder and concrete slab. For example, Figs 6 and 7 show the first and second mode shapes for four damage scenarios, respectively. For both modes, the mode shapes for DS1 show that the vibration directions of slab and girder become opposite. The results may indicate that the method proposed by Xia et al. (2007) is suitable for shear connector damage identification in a slab-girder structure. However, the shapes of the first mode for DS2 and DS3 do not show any apparent discrepancy. The shapes of the second mode for DS2 and DS3 show that there is discrepancy between slab and girder, but this discrepancy is not as large as the results for DS1. The reason may be that the end bolts have the biggest influence on the vibration results. The changes of mode shapes are very complex, and therefore the appropriate application of this method needs further studies.

Table 2 Vibration test results in Stage 1

\begin{tabular}{|l|l|l|l|l|l|}
\hline \multirow{2}{*}{ Mode No. } & \multirow{2}{*}{ Mode shape Description } & \multicolumn{5}{|l|}{ Natural frequency results in different damage scenarios } \\
\cline { 3 - 6 } & & DS0 (Hz) & DS1 (Hz/change\%) & DS2 (Hz/change\%) & DS3 (Hz/change\%) \\
\hline
\end{tabular}




\begin{tabular}{|c|c|c|c|c|c|c|c|c|}
\hline $1 \#$ & Bending & 10.64 & 10.64 & $0.00 \%$ & 10.64 & $0.00 \%$ & 10.64 & $0.00 \%$ \\
\hline 2\# & Bending & 31.34 & 31.39 & $0.16 \%$ & 31.4 & $0.19 \%$ & 31.17 & $-0.54 \%$ \\
\hline 3\# & Torsional & 43.38 & 43.38 & $0.00 \%$ & 43.39 & $0.02 \%$ & 43.37 & $-0.02 \%$ \\
\hline $4 \#$ & Bending & 51.52 & 51.67 & $0.29 \%$ & 51.45 & $-0.14 \%$ & 51.28 & $-0.47 \%$ \\
\hline $5 \#$ & Bending & 78.76 & 79.12 & $0.46 \%$ & 78.53 & $-0.29 \%$ & 78.85 & $0.11 \%$ \\
\hline $6 \#$ & Torsional & 89.74 & 89.79 & $0.06 \%$ & 89.7 & $-0.04 \%$ & 89.59 & $-0.17 \%$ \\
\hline $7 \#$ & Local & 120.25 & 120.02 & $-0.19 \%$ & 119.55 & $-0.58 \%$ & 119.22 & $-0.86 \%$ \\
\hline 8\# & Local & 137.31 & 136.45 & $-0.63 \%$ & 136.46 & $-0.62 \%$ & 136.24 & $-0.78 \%$ \\
\hline 9\# & Bending & 170.26 & 168.87 & $-0.82 \%$ & 167.39 & $-1.69 \%$ & 168.54 & $-1.01 \%$ \\
\hline $10 \#$ & Bending & 172.29 & 171.87 & $-0.24 \%$ & 171.79 & $-0.29 \%$ & 171.85 & $-0.26 \%$ \\
\hline $11 \#$ & Torsional & 187.61 & & & & & & \\
\hline $12 \#$ & Local & 241.9 & & & & & & \\
\hline 13\# & Bending & 291.51 & 288.05 & $-1.19 \%$ & 284.63 & $-2.36 \%$ & 287.86 & $-1.25 \%$ \\
\hline $14 \#$ & Bending & 358.79 & 356.31 & $-0.69 \%$ & 352.27 & $-1.82 \%$ & 353.74 & $-1.41 \%$ \\
\hline $15 \#$ & Torsional & 406.67 & 405.85 & $-0.20 \%$ & 405.12 & $-0.38 \%$ & 406.33 & $-0.08 \%$ \\
\hline 16\# & Local & 438.36 & 436.56 & $-0.41 \%$ & 435.18 & $-0.73 \%$ & 435.49 & $-0.65 \%$ \\
\hline $17 \#$ & Torsional & 471.61 & 473.2 & $0.34 \%$ & 473.1 & $0.32 \%$ & 470.14 & $-0.31 \%$ \\
\hline $18 \#$ & Local & 514.8 & 513.07 & $-0.34 \%$ & 509.68 & $-0.99 \%$ & 510.27 & $-0.88 \%$ \\
\hline 19\# & Local & 617.08 & 615.7 & $-0.22 \%$ & 611.3 & $-0.94 \%$ & 613.02 & $-0.66 \%$ \\
\hline $20 \#$ & Local & 674.15 & 671.93 & $-0.33 \%$ & 669.12 & $-0.75 \%$ & 671.22 & $-0.43 \%$ \\
\hline $21 \#$ & Local & 694.08 & & & & & & \\
\hline $22 \#$ & Local & 707.22 & 703.88 & $-0.47 \%$ & 700.77 & $-0.91 \%$ & 702.22 & $-0.71 \%$ \\
\hline 23\# & Torsional & 755.74 & 753.78 & $-0.26 \%$ & 751.06 & $-0.62 \%$ & 752.64 & $-0.41 \%$ \\
\hline $24 \#$ & Local & 762.64 & 762.62 & $0.00 \%$ & & & & \\
\hline $25 \#$ & Local & 793.04 & & & & & & \\
\hline $26 \#$ & Torsional & 840.85 & 840.43 & $-0.05 \%$ & 837.25 & $-0.43 \%$ & 838.58 & $-0.27 \%$ \\
\hline $27 \#$ & Local & 921.41 & & & & & & \\
\hline $28 \#$ & Torsional & 934.65 & 933.85 & $-0.09 \%$ & 931.71 & $-0.31 \%$ & 932.63 & $-0.22 \%$ \\
\hline
\end{tabular}




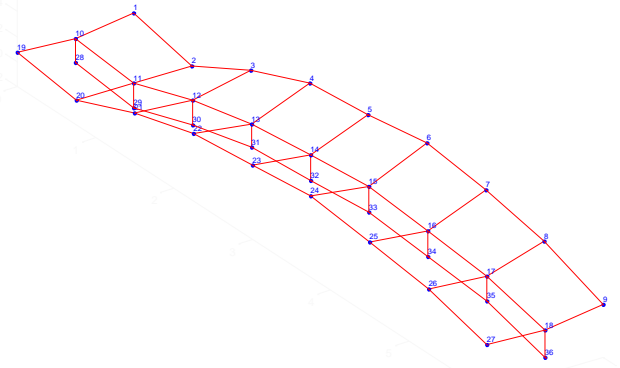

a) DS0

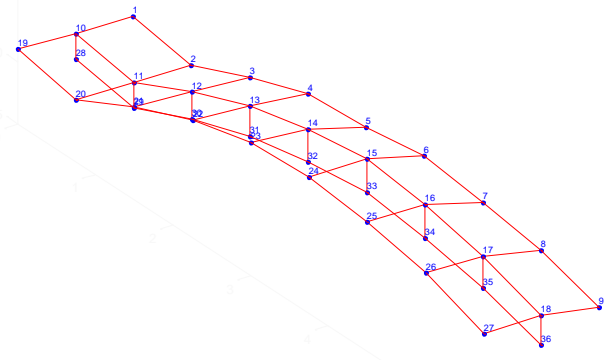

c) DS2

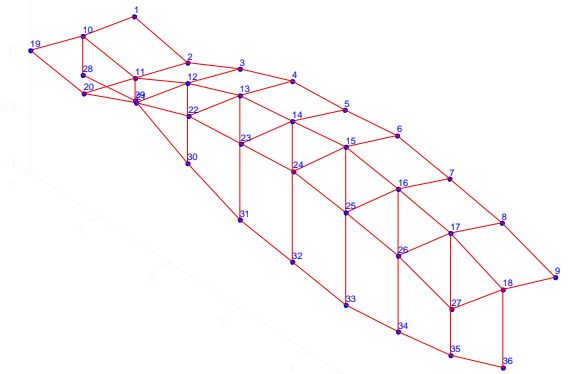

b) DS1

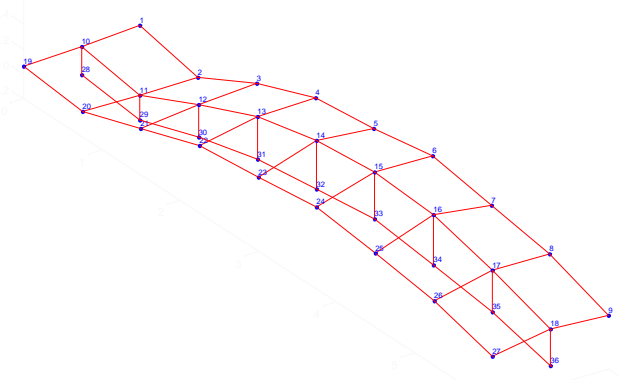

d) DS3

Figure 6 First mode of the slab-girder system to damage scenarios of DS0, DS1, DS2, and DS3

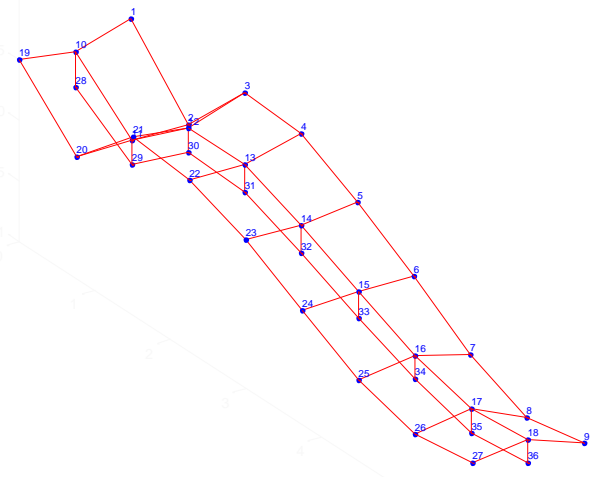

a) DS0

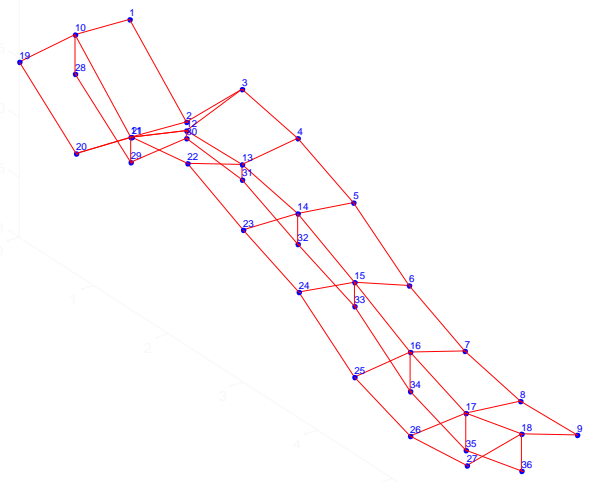

c) DS2

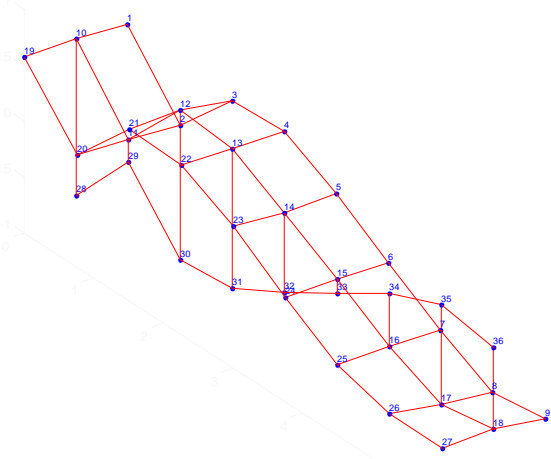

b) DS1

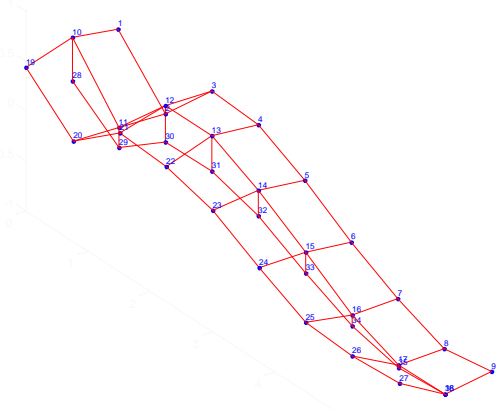

d) DS3

Figure 7 Second mode of the slab-girder system to damage scenarios of DS0, DS1, DS2, and DS3 


\section{Stage 2}

\section{Static test results}

In the second stage, all the removable bolts were removed and then vibration tests for DS4 were conducted. After that, two sets of hydraulic equipment were set up to provide four point static loadings on the slab-girder structure. The structure was loaded twice. In the first time, the structure was loaded to $17 \mathrm{kN}$ and then unloaded. This load is chosen to represent the service load. Based on theoretical calculations, it will not induce any visible crack on the concrete slab. The impact hammer tests were conducted and the results show that the natural frequencies and mode shapes are the same as DS4. These demonstrate that the structure was still under linear elastic state.

In the second time, the structure was loaded until concrete cracked. The static loading and deflection histories are shown in Fig. 8. Based on theoretical results, it is found that if there is no interaction between concrete and steel, concrete slab will crack in its tension zone when load $P$ is larger than $4.17 \mathrm{kN}$. While if full interaction is considered, the failure loading will be $45.71 \mathrm{kN}$, ten times larger than the former result. As can be seen in Fig. 8(a), the failure load is $42 \mathrm{kN}$ and $40 \mathrm{kN}$ for south and north loadings, respectively. The values are close to the theoretical results when the girder and slab is fully connected, demonstrating that the load-carrying capacity of the composite slab-girder system will drop slightly even after a large numbers of shear connectors are damaged (provided that a number of connectors are still working). Specifically, all the removable shear connectors (Figure 1(d)) are removed, representing that $60 \%$ of shear connectors are damaged.

By deducting the support deflections, the final displacement in the middle point is around $54 \mathrm{~mm}$. The theoretical deflection results lie in the range between $16 \mathrm{~mm}$ and $116 \mathrm{~mm}$ with and without shear connectors, respectively. This result indicates that the stiffness of the composite slab-girder system may drop substantially after a number of shear connectors are damaged.

As can be seen in Fig. 8(b), the deflection at the middle point increased fast from $28 \mathrm{~mm}$ to $54 \mathrm{~mm}$ in the time span of $1928 \mathrm{~s}$ to $2052 \mathrm{~s}$. In this time range, the final 
loading step was just performed; concrete started cracking; and the structure nearly reached its load-carrying capacity. There are mainly two cracks, which are located at $13 \mathrm{~cm}$ and $16 \mathrm{~cm}$ to the loading points respectively. The locations coincide with where the last row of the headed studs is located at. The largest crack width is $8 \mathrm{~mm}$. The cracked structure is shown in Fig. 9.

The relative displacements between slab and girder at various locations were also recorded. For example, the results from Lasers 1 and 3 are shown in Fig. 8(c). Theoretically, the relative displacement should be very small when slab and girder are fully connected. When some of the shear connectors were removed, as can be seen, relative displacement between slab and girder at the beam end became very prominent. During the early stage of loading, the relative displacement increases steadily with the loading. From 1928s to 2052s, coinciding with the sharp increase in vertical displacement, the relative displacement increases dramatically from 2.5 $\mathrm{mm}$ to $7 \mathrm{~mm}$. This sharp increase in the relative displacement can be used as an indicator of composite structure damage. Compared with the middle point displacement, the advantages of using the relative displacement include that it is very easy to be measured and no reference point is needed. So it may be a better indicator for monitoring purposes. Further experimental verification studies are needed.

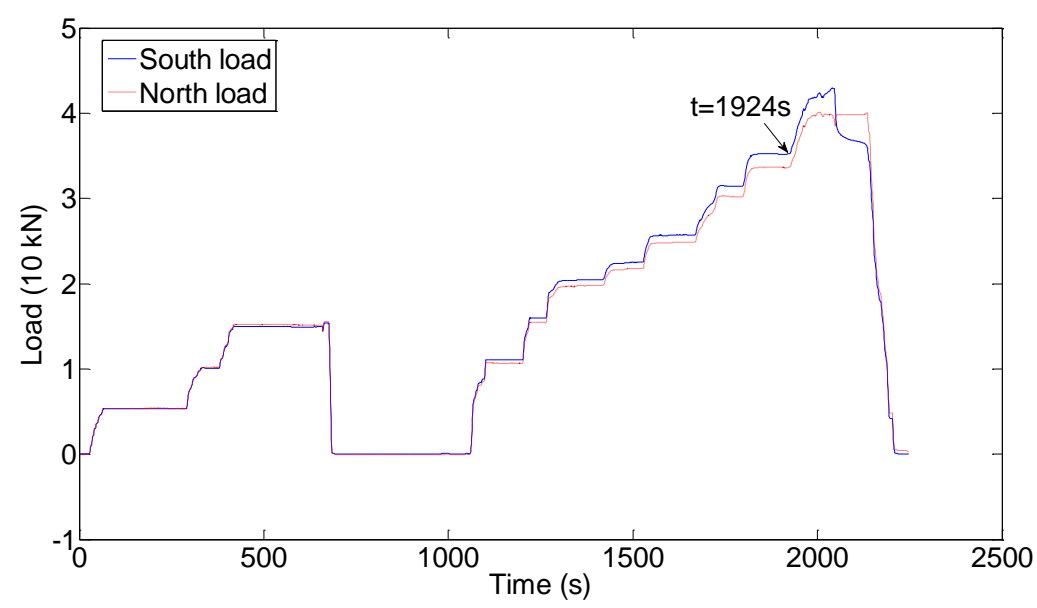

a) Load history 


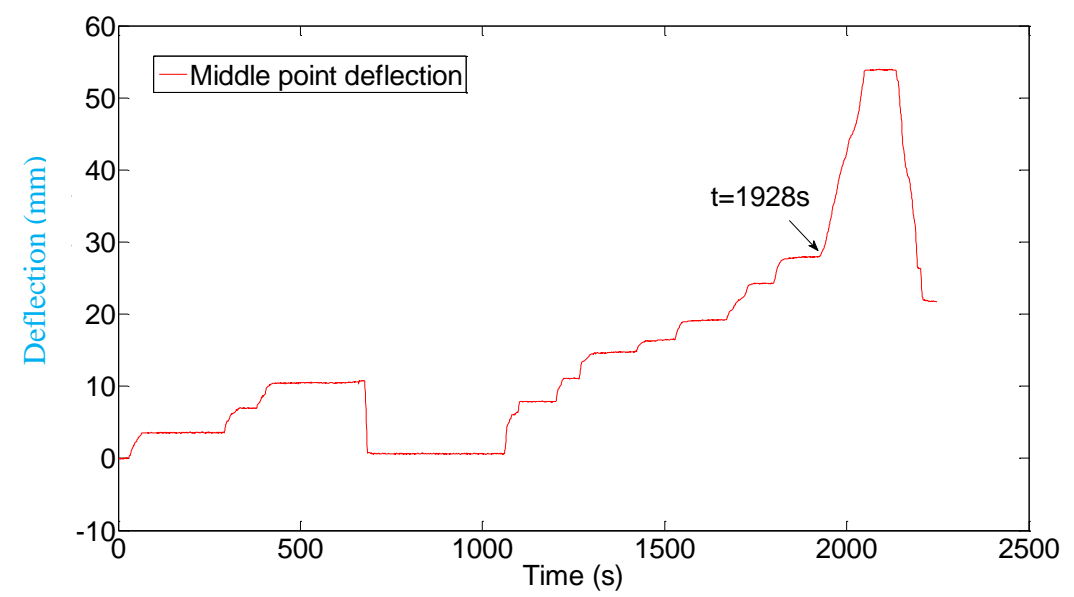

b) Middle point deflection history

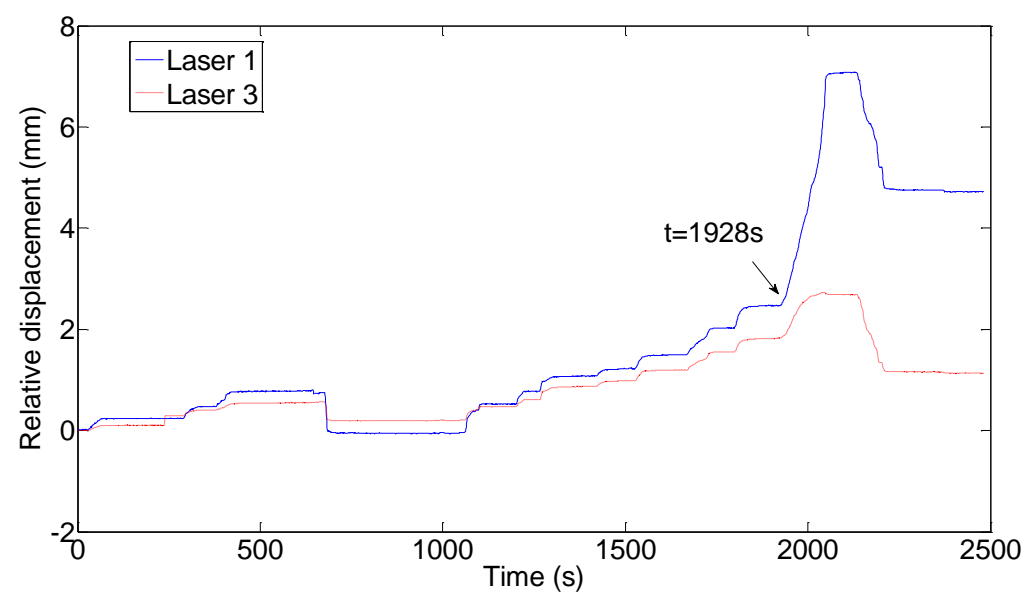

c) Relative displacements between slab and girder (from lasers 1 and 3)

Figure 8 Static test results

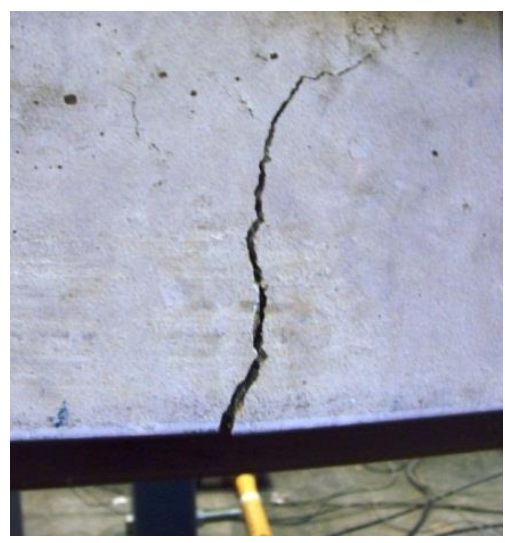

a) Side view

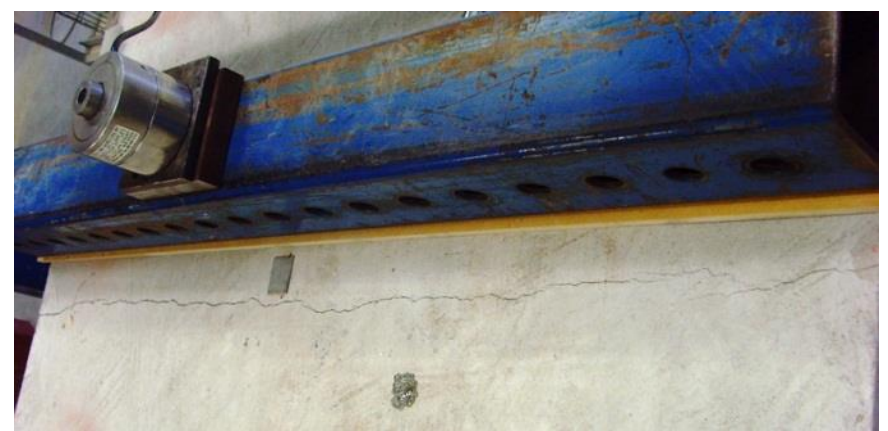

b) Top view

Figure 9 Damaged structure 


\section{Vibration test results}

For the second stage, more modes cannot be identified and larger changes of the natural frequencies can be found. As can be seen in Table 3, for DS4, 18 modes are identified, including 5 bending modes, 7 torsional modes and 6 local modes. The change of the first bending mode is $-3.01 \%$, implying that the structural stiffness becomes lower if there is no adequate shear connector between steel girder and concrete slab. For DS5, only 12 modes are identified, including 3 bending modes, 4 torsional modes and 5 local modes. The change of the first bending mode is $20.68 \%$, meaning that the structural stiffness decreases significantly when concrete slab cracks. In fact, under this condition, the structure will not be suitable for carrying loads. The first and second mode shapes for DS4 and DS5 are shown in Figs 10 and 11, respectively. As can be seen, although the first mode becomes irregular, the second mode shows more discrepancy. In fact, under scenarios with big damages (DS4 and DS5), natural frequencies are more suitable for damage identification.

Table 3 Vibration test results in Stage 2

\begin{tabular}{|c|c|c|c|c|c|c|}
\hline \multirow{3}{*}{$\begin{array}{c}\text { Mode No. } \\
1 \#\end{array}$} & \multirow{3}{*}{$\begin{array}{c}\text { Mode shape Description } \\
\text { Bending }\end{array}$} & \multicolumn{5}{|c|}{ Natural frequency results in different damage scenarios } \\
\hline & & \multirow{2}{*}{$\begin{array}{c}\text { DS0 }(\mathrm{Hz}) \\
10.64\end{array}$} & \multicolumn{2}{|c|}{ DS4 (Hz/change\%) } & \multicolumn{2}{|c|}{ DS5 (Hz/change\%) } \\
\hline & & & 10.32 & $-3.01 \%$ & 8.44 & $-20.68 \%$ \\
\hline $2 \#$ & Bending & 31.34 & 30.05 & $-4.12 \%$ & 25.07 & $-20.01 \%$ \\
\hline $3 \#$ & Torsional & 43.38 & 42.88 & $-1.15 \%$ & & \\
\hline $4 \#$ & Bending & 51.52 & 48.28 & $-6.29 \%$ & & \\
\hline $5 \#$ & Bending & 78.76 & & & & \\
\hline $6 \#$ & Torsional & 89.74 & & & 82.43 & $-8.15 \%$ \\
\hline $7 \#$ & Local & 120.25 & 111.96 & $-6.89 \%$ & & \\
\hline $8 \#$ & Local & 137.31 & 136.62 & $-0.50 \%$ & 132.76 & $-3.31 \%$ \\
\hline 9\# & Bending & 170.26 & 157.45 & $-7.52 \%$ & & \\
\hline $10 \#$ & Bending & 172.29 & & & & \\
\hline 11\# & Torsional & 187.61 & 186.46 & $-0.61 \%$ & 175.3 & $-6.56 \%$ \\
\hline $12 \#$ & Local & 241.9 & & & 220.43 & $-8.88 \%$ \\
\hline 13\# & Bending & 291.51 & 270.21 & $-7.31 \%$ & & \\
\hline
\end{tabular}




\begin{tabular}{|c|c|c|c|c|c|c|}
\hline $14 \#$ & Bending & 358.79 & & & 339.48 & $-5.38 \%$ \\
\hline $15 \#$ & Torsional & 406.67 & 404.56 & $-0.52 \%$ & 392.82 & $-3.41 \%$ \\
\hline $16 \#$ & Local & 438.36 & 429.96 & $-1.92 \%$ & 405.41 & $-7.52 \%$ \\
\hline $17 \#$ & Torsional & 471.61 & 469.19 & $-0.51 \%$ & & \\
\hline $18 \#$ & Local & 514.8 & 515.23 & $0.08 \%$ & 475.17 & $-7.70 \%$ \\
\hline 19\# & Local & 617.08 & & & 561.71 & $-8.97 \%$ \\
\hline $20 \#$ & Local & 674.15 & & & & \\
\hline $21 \#$ & Local & 694.08 & & & & \\
\hline $22 \#$ & Local & 707.22 & 687.97 & $-2.72 \%$ & & \\
\hline $23 \#$ & Torsional & 755.74 & 748.52 & $-0.96 \%$ & & \\
\hline $24 \#$ & Local & 762.64 & & & & \\
\hline $25 \#$ & Local & 793.04 & & & & \\
\hline $26 \#$ & Torsional & 840.85 & 835.68 & $-0.61 \%$ & & \\
\hline $27 \#$ & Local & 921.41 & 893.81 & $-3.00 \%$ & & \\
\hline $28 \#$ & Torsional & 934.65 & 929.51 & $-0.55 \%$ & 891.66 & $-4.60 \%$ \\
\hline
\end{tabular}

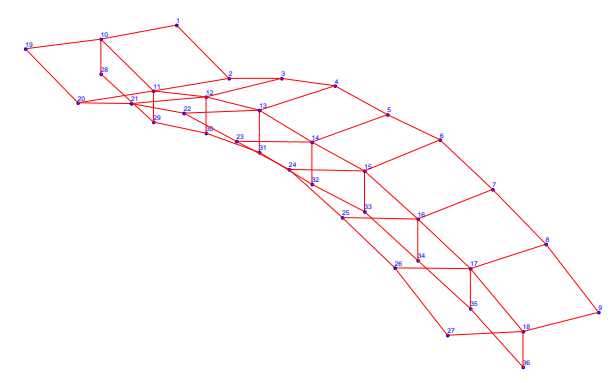

a) DS4

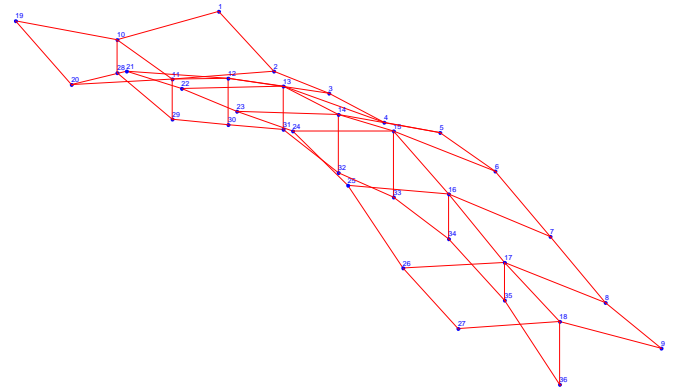

b) DS5

Figure 10 First mode of the slab-girder system to damage scenarios of DS4 and DS5 


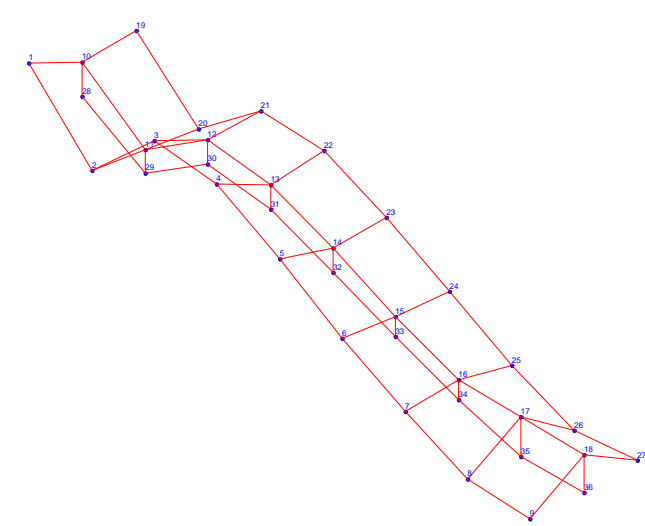

a) DS4

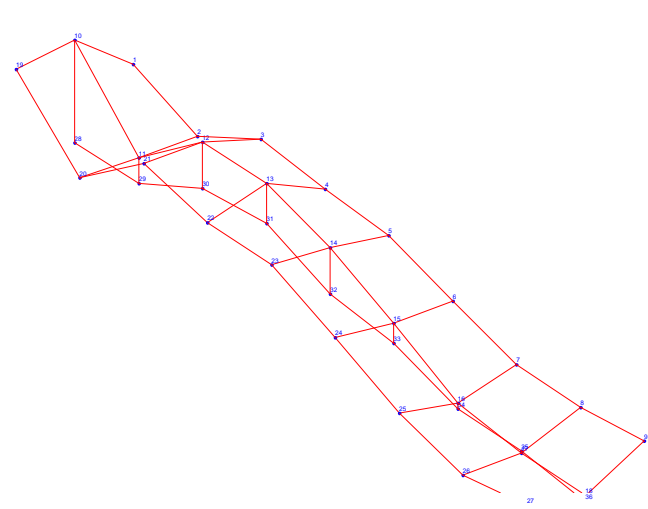

b) DS5

Figure 11 Second mode of the slab-girder system to damage scenarios of DS4 and DS5

\section{CONCLUSIONS}

A composite slab-girder system with removable shear connectors was constructed in the laboratory. Static and vibration tests were performed in two stages under different damage scenarios. Based on the vibration test results, the severer the damage is, the fewer modes can be identified. The natural frequencies are not sensitive to the shear connector damage. However, the inconsistency of the mode shapes between concrete slab and steel girder may be a prominent feature for damage identification. Based on the static test results, when many shear connectors are damaged, the load-carrying capacity of a slab-girder structure may decrease slightly, but its stiffness will be largely reduced. The relative displacement between slab and girder at the beam end is another promising indicator for shear connector damage of this kind of structures. Further studies, especially numerical models, are needed for more detailed damage identification, which will be investigated in the near future.

\section{REFERENCES}

1. Bao C.X., Hao H., Li Z.X. and Zhu X.Q. (2009) "Time-varying system identification using a newly improved HHT algorithm." Computers and Structures, Vol. 87, No. 23-24, pp. 16111623

2. Dilena M. and Morassi A. (2003) "A damage analysis of steel-concrete composite beams via dynamic methods: part II. Analytical models and damage detection.” Journal of Vibration and Control, Vol. 9, pp.529-565 
3. Dilena M. and Morassi A. (2009) "Vibrations of steel-concrete composite beams with partially degraded connection and applications to damage detection.” Journal of Sound and Vibration, Vol. 320, No. 1-2, pp. 101-124

4. Doebling S.W., Farrar C.R. and Prime M.B. (1998) "A summary review of vibration based damage identification methods." Shock and Vibration Digest, 30(2), 91-105.

5. Johnson R. P. (2004) Composite Structures of Steel and Concrete: Beams, Slabs, Columns, and Frames for Buildings, 3rd Edition, Wiley-Blackwell

6. Liu K. and De Roeck G. (2009) "Damage detection of shear connectors in composite bridges." Structural Health Monitoring, 8(5), 345-356

7. Los Alamos National Laboratory (LANL) Diamond Software, http://institute.lanl.gov/ei/software-and-data/diamond/

8. Morassi A. and Rocchetto L. (2003) "A damage analysis of steel-concrete composite beams via dynamic methods: part II. Experimental results.” Journal of Vibration and Control, Vol. 9, pp. $507-527$

9. Ren W.X., Sun Z.S., Xia Y., Hao H. and Deeks A.J. (2008) "Damage identification of shear connectors with wavelet packet energy: laboratory test study." Journal of Structural Engineering, ASCE, 134(5), 832-841

10. Shih H.W., Thambiratnam D.P. and Chan T.H.T. (2012) "Damage detection in slab-on-girder using vibration characteristics." Structural Control and Health Monitoring, DOI: $10.1002 /$ stc. 1535

11. Sohn H., Farrar C.R., Hemez F.M., Czarnecki J.J., Shunk D.D., Stinemates D.W., Nadler B.R. (2003) “A review of structural health monitoring literature: 1996-2001.” Los Alamos National Laboratory Report; LA-13976-MS.

12. Standards Australia (2003) Australian Standard AS 2327.1-2003. Composite structures-simply supported beam. Standards Australia International Ltd.

13. Xia Y., Hao H. and Deeks A.J. (2007) "Dynamic assessment of shear connectors in slab-girder bridges.” Engineering Structures, 29 (7), pp. 1475-1486

14. Xia Y., Hao H., Deeks A.J. and Zhu X.Q. (2008) "Condition assessment of shear connectors in slab-girder bridges via vibration measurements.” Journal of Bridge Engineering, ASCE, 13 (1), pp. $43-54$

15. Zhu X.Q., Hao H., Uy B., Xia Y. and Mirza O. (2012) "Dynamic assessment of shear connection conditions in slab-girder bridges by Kullback-Leibler Distance." Advances in Structural Engineering, 15(5), pp. 771-780 